\title{
The impact of HIV infection on adult mortality in some communities in Zambia: a cohort study
}

\author{
Kumbutso Dzekedzeke ${ }^{1,2}$, Seter Siziya ${ }^{3}$ and Knut Fylkesnes ${ }^{2}$ \\ 1 Central Statistical Office, Lusaka, Zambia \\ 2 Centre for International Health, University of Bergen, Bergen, Norway \\ 3 Department of Community Medicine, School of Medicine, University of Zambia, Lusaka, Zambia
}

Summary OBJECTIVE To examine the contribution of human immunodeficiency virus (HIV) to adult death rates between 1995/1996 and 1998/1999 in some urban and rural populations in Zambia.

METHOD A cohort of 2592 out of 3013 adults aged 15-49 years enrolled in a baseline survey in 1995/1996 in areas of Chelston Township (HIV prevalence 26.2\%) and Kapiri Mposhi district (HIV prevalence $15.6 \%$ ) were followed up in 1998/1999. Person years of observation (PYO) were calculated for those known to have been alive, dead and migrated between the surveys. Fixed covariates Cox proportional hazard models were fitted to assess survival prospects.

RESUlTS Death rates per 1000 PYO in the rural cohort were 38.1 among those with HIV, 4.8 among those without HIV and 9.8 for all; the population attributable fraction of deaths among those with HIV was 52.3\%. Respective estimates in the urban cohort were 53.8, 4.6, 17.2 and 73.6\%. The hazard rate (HR) ratio of death for persons infected with HIV was 8.7 times [HR $8.65 ; 95 \%$ confidence interval (CI) 5.28-14.15] higher than for the uninfected after adjusting for age, area of residence, marital status, self-rated health and years spent on education. HR among those who rated their health good/excellent was 40\% less, i.e. HR 0.60 (95\% CI: 0.40-0.91) than those who rated it to be poor/fair. CONCLUSIONS HIV infection was the most important factor accounting for adult deaths in the communities.

keywords human immunodeficiency virus, Zambia, adult mortality

\section{Introduction}

Studies which directly identified deaths by HIV status have shown that the steep increase in adult mortality in most sub-Saharan countries since the late 1980s is attributed to human immunodeficiency virus (HIV) (Mulder et al. 1994; Sewankambo et al. 1994, 2000; Nunn et al. 1997; Todd et al. 1997; Pictet et al. 1998; Urassa et al. 2001; Lopman et al. 2006). These studies seem to suggest that the level of HIV prevalence is the major determinant of total death rates among adults in these sub-Saharan countries. Prevalence in the Kisesa cohort at about 7\% among both men and women (Urassa et al. 2001) was less than half of that in other cohorts and the total death rates were also much lower than in the other cohorts. However, there was no clear pattern in the differences in death rates among the infected and among the uninfected. This indicates that there could have been artefacts peculiar to the studies in the way deaths were identified to be HIV related or not. A move towards standardizing these studies in the future would be useful.

Studies which did not identify deaths by HIV status also found a strong positive relationship between HIV prevalence and adult mortality levels, an indication that HIV was the major cause of the deaths (Timaeus 1998; Blacker 2004; Notkola et al. 2004; Timaeus \& Jasseh 2004). Data from demographic and health surveys have revealed that the range of adult mortality levels in sub-Saharan countries was wider in the mid-1990s than a decade earlier (Timaeus \& Jasseh 2004). The divergent pace at which HIV spread among the communities is not clearly understood (Piot et al. 1988; Quinn et al. 2001).

In Zambia, the death rate among those aged 15-49 years increased from 11.7 to 14.8 among women and from 12.9 to 13.9 among men per 1000 person years of observation (PYO) between 1996 and 2002 [Central Statistical Office (Zambia) et al. (2003)]. The women's death rate surpassed that of men probably owing to the higher HIV prevalence 
K. Dzekedzeke et al. Impact of HIV on adult mortality in Zambia

among them. Prevalence was estimated at (17.8\%) among women and (12.9\%) among men in 2001-2002 [Central Statistical Office (Zambia) et al. (2003)]. However, these death rate estimates do not specify the contribution of deaths among those who had HIV in Zambia. Therefore, based on a prospective cohort population survey (Fylkesnes \& Kasumba 1998; Fylkesnes et al. 1998, 2001), we examined death rates of adults 15-49 years by HIV status over 3 years between 1995/1996 and 1998/1999 in some urban and rural populations in Zambia.

\section{Methods}

\section{Study population}

The cohort was enrolled in Kapiri Mposhi district and Chelston Township in a baseline population survey conducted in 1995/1996. The survey was conducted in October-December 1995 in Chelston and in JanuaryMarch 1996 in Kapiri Mposhi (Fylkesnes et al. 1998). Chelston is an urban residential area of Lusaka. Kapiri Mposhi district, about $250 \mathrm{~km}$ north of Lusaka, has a peri-urban and village population. The cohort was enrolled from households in clusters selected by stratified random cluster sampling in purposively identified communities during an HIV prevalence survey (Fylkesnes et al. 1998, 2001). All households in the clusters were contacted and household members 15 years and older were listed after an interview. Those listed were eligible for a saliva HIV test after counselling, although some were not tested because they did not consent (Fylkesnes et al. 1998). The listing used in the initial survey enabled individual links with information about survival, migration and other follow-up status collected in a follow-up survey. The follow-up survey was carried out together with the second prevalence survey in the same clusters as the baseline prevalence survey. As the prevalence survey was separate from the cohort follow-up survey, the change in HIV status of subjects in the cohort whose HIV status was unambiguous during the baseline survey could not be determined. The follow-up survey was subjects listed in the initial survey were recorded in the follow-up survey.

Potential bias from losses to follow up was assessed by comparing the per cent distribution of followed up and lost to follow-up subjects by sex. Differences in infection patterns by sex were observed in the baseline survey (Fylkesnes et al. 1998). We also compared variables strongly associated with survival status, namely: age, educational level, employment status, rural or urban residence (United Nations Dept. of Economic and Social Affairs 1973), marital status (Hu \& Goldman 1990; Lillard \& Panis 1996; Noale et al. 2005) and self-rated heath status (Idler \& Benyamini 1997). Confidence intervals (CI) for the percentages of subjects with HIV were set at $95 \%$ and took into account the cluster effect in the sample selection.

\section{Death rate estimates}

The date of interview in the first survey, the date of migration or death and the date of interview of subjects surviving by the time of the second survey were used to compute the PYO. Out-migrants were censored at the time they left the communities if their date of migration was obtained. Subjects whose post-baseline information could not be obtained were lost to follow up. Death rates were estimated per 1000 PYO. Given the small number of cases, Poisson $95 \%$ CI were calculated for the mortality rate ratios (Gerstman 1998). The total death rates $\left({ }_{35} \mathrm{~m}_{15}\right)$ were converted into the probability of death between 15 and 50 years $\left({ }_{35} \mathrm{q}_{15}\right)$ (Preston et al. 2001).

The mortality rate ratios (MRR) of deaths for those with HIV infection relative to those without HIV infection were computed in order to estimate the relative excess of deaths associated with HIV infection. The population attributable fraction (PAF) of deaths owing to HIV infection was also estimated in order to assess potential deaths that could be averted without HIV infection. More than half of deaths in those infected with HIV were attributed to a co-morbidity mediated by HIV (Mulder et al. 1994; Todd et al. 1997; Sewankambo et al. 2000). Therefore, the PAF was based on the formula originally reported by Levin which focusses on

$$
P A F(\%)=\left\{H I V(\%)\left[\left(\frac{D R I}{D R U}\right)-1\right] \div\left[1+H I V(\%)\left(\frac{D R I}{D R U}\right)-1\right]\right\} \times 100
$$

carried out between mid-October 1998 and the end of May 1999 (Fylkesnes et al. 2001). If known, the date of migrating out of the study area and date of death of the attributable risk in the total population owing to the infection (Levin 1953). The formula was fitted as: where;

$\mathrm{HIV} \%=\mathrm{HIV}$ prevalence ratio 
K. Dzekedzeke et al. Impact of HIV on adult mortality in Zambia

DRI $=$ death rate among the infected

DRU $=$ death rate among the uninfected.

\section{Standardized total estimates}

The total age-sex standardized death rates and percentages of subjects with HIV were calculated by the direct method. The total populations listed by sex in the baseline survey were used as the standard in order to assess potential biases in the total death rates that could be caused by losses to follow up of subjects in the cohort.

\section{Statistical analysis}

Data were analysed using the Statistical Package for Social Sciences (sPSS version 13.0 for Windows; SPSS, Chicago, Illinois, USA). Microsoft Excel Spreadsheet (Microsoft Incorporation, Washington, USA) was also used to analyse data. Data analysis was restricted to those aged 1549 years because there were no followed up HIV-infected women in urban areas older than 49 years.

Kaplan-Meier survival plots from enrollment time to death tested for statistical significance with the log-rank Mantel-Cox chi-squared test were plotted by sex and area of residence. As the cause of death among those infected with HIV was not determined, a fixed covariate Cox hazard regression (likelihood ratio) model was used to further assess the importance of HIV status on the survival of adults. Selected variables which affect the survival of adults were fitted in univariate survival models. In addition to HIV status, selected covariates were age group, ruralurban residence, self-rated health (included as a dichotomous variable, very poor/poor/fair and good/excellent) and years spent on education at baseline survey. PYO were 6386 with 97 deaths. This restricted the number of variables to be included in the multivariate models. At least 10 events need to be observed for each covariate to avoid obtaining biased regression coefficients (Peduzzi et al. 1995). As a result, it was also not feasible to stratify the models. Log-log plots for survival end points by covariate in univariate models were inspected to assess the proportionality of hazards over time at the mean of each covariate. Significant variables from the univariate models were fitted in two multivariate Cox hazard models.

In one multivariate model, variables were adjusted for HIV status and in the other, they were not. The objective of the first multivariate model was to assess the change in the HR of each survival covariate after controlling for potential confounding from other significant covariates but without controlling for HIV status. The second multivariate model was fitted in the same way as the first multivariate model, but HIV status was also controlled for.
In the second model, the effect of other significant covariates on survival prospects by HIV status were also controlled for. All statistical tests used two-sided $P$ values with the level of statistical significance set at $5 \%$. However, some covariates slightly outside this limit were also considered to be significant.

\section{Results}

In the baseline survey in 1995/1996, 3013 persons aged 15-49 years were interviewed and had an unambiguous HIV test result. In the follow-up survey of $1998 / 1999$, $2592(86.0 \%)$ were identified in $1998 / 1999$ as residents in the same area or date of out-migration or date of death. Ninety-seven (3.7\%) had died and 1244 (48\%) had migrated from the area. Prevalence in the baseline cohort and the follow-up population did not differ significantly: rural 16.7 vs. 15.6, and urban 26.5 vs. 26.2. Furthermore, the total HIV prevalence among those who out-migrated $(22.6 \%)$ was similar to the followed-up population $(23.8 \%)$.

As shown in Table 1, the HIV status of persons lost to follow up was not significantly different from those followed up. There were bigger differences in the percentage infected between those followed up and those lost to follow up among males who were divorced/separated/widowed, with very poor/poor/fair self-rated health and with 12 or more years of education. Among females, the biggest difference was among those with $10-11$ years of education. The percentage with HIV also tended to be higher among men lost to follow up than among men who were followed up, although the differences were not statistically significant. The opposite was the case among women such that the total percentage with HIV among those lost to follow up was lower among women but higher among men although this was not statistically significant. Among men 15-49 years who were followed up, 18.7\% were infected with HIV compared with $23.8 \%$ among those lost to follow up. Among women 15-49 years who were followed up, $26.2 \%$ were infected with HIV compared with $25.5 \%$ among those lost to follow up.

As shown in Table 2, the peak prevalence of HIV in the followed-up population at baseline was in the 25-34 years age group in both rural and urban areas. The death rate for the infected was consistently higher than for the uninfected. While the death rate among the infected peaked in the age group 25-34 years in the rural cohort, it increased with age group in the urban cohort. The MRR among men was about twice as high as among women in the rural cohort and about $46 \%$ higher among men than women in the urban cohort. The total PAF was higher in urban than rural areas just as the HIV prevalence levels. This was also 
K. Dzekedzeke et al. Impact of HIV on adult mortality in Zambia

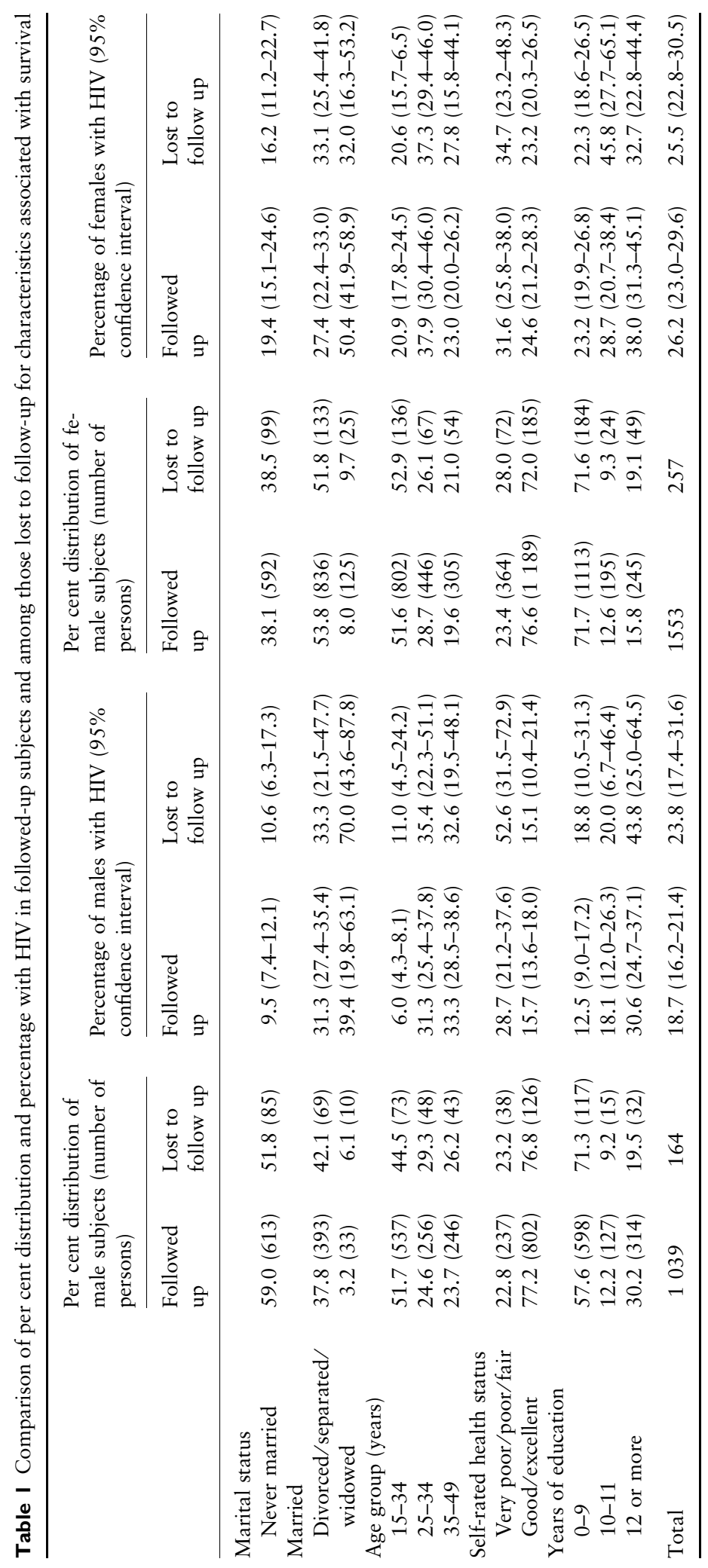


K. Dzekedzeke et al. Impact of HIV on adult mortality in Zambia

Table 2 Human immunodeficiency virus (HIV) prevalence in cohort population, death rates by HIV status, mortality rate ratio $(95 \%$ Poisson CI) for those with HIV relative to those without HIV, PAF of deaths among those with HIV and their age standardized total rates for persons $15-49$ years

\begin{tabular}{|c|c|c|c|c|c|c|c|c|c|c|c|c|}
\hline & \multirow[b]{2}{*}{$\begin{array}{l}\text { HIV } \\
\text { prevalence }\end{array}$} & \multicolumn{3}{|c|}{ Without HIV } & \multicolumn{3}{|c|}{ With HIV } & \multicolumn{3}{|l|}{ Total } & \multirow[b]{2}{*}{$\begin{array}{l}\text { Mortality } \\
\text { rate ratio }\end{array}$} & \multirow[b]{2}{*}{$\operatorname{PAF}(\%)$} \\
\hline & & PYO & Deaths & $\begin{array}{l}\text { Death } \\
\text { rate }\end{array}$ & PYO & Deaths & $\begin{array}{l}\text { Death } \\
\text { rate }\end{array}$ & PYO & Deaths & $\begin{array}{l}\text { Death } \\
\text { rate }\end{array}$ & & \\
\hline \multicolumn{13}{|l|}{ Rural } \\
\hline $15-24$ & 10.7 & 712 & 4 & 5.6 & 91 & 1 & 11.0 & 803 & 5 & 6.2 & $2.0(0.7-55.5)$ & 9.3 \\
\hline $25-34$ & 23.4 & 397 & 0 & 0 & 104 & 6 & 57.6 & 501 & 6 & 12.0 & $\infty$ & 100 \\
\hline $35-49$ & 16.1 & 364 & 3 & 8.2 & 67 & 3 & 44.6 & 431 & 6 & 13.9 & $5.4(1.1-26.8)$ & 41.5 \\
\hline Men & 14.7 & 646 & 2 & 3.1 & 110 & 5 & 45.2 & 756 & 7 & 9.3 & $14.6(2.8-75.3)$ & 66.6 \\
\hline Standardized & 15.9 & & & 2.4 & & & 33.8 & & & 9.7 & 13.8 & 67.1 \\
\hline Women & 16.3 & 827 & 5 & 6.0 & 152 & 5 & 33.0 & 979 & 10 & 10.2 & $5.5(1.6-19.0)$ & 42.1 \\
\hline Standardized & 16.7 & & & 6.2 & & & 34.8 & & & 10.5 & 5.6 & 43.7 \\
\hline Total & 15.6 & 1473 & 7 & 4.8 & 262 & 10 & 38.1 & 1736 & 17 & 9.8 & $8.0(2.5-5.5)$ & 52.3 \\
\hline Standardized & 16.2 & & & 4.5 & & & 34.8 & & & 10.1 & 7.7 & 52.1 \\
\hline \multicolumn{13}{|l|}{ Urban } \\
\hline $15-24$ & 16.5 & 2008 & 6 & 3.0 & 373 & 14 & 37.5 & 2381 & 20 & 8.4 & $12.6(4.8-32.8)$ & 65.6 \\
\hline $25-34$ & 40.8 & 747 & 3 & 4.0 & 485 & 28 & 57.8 & 1231 & 31 & 25.2 & $14.4(4.4-47.4)$ & 84.5 \\
\hline $35-49$ & 32.9 & 706 & 7 & 9.9 & 332 & 22 & 66.3 & 1037 & 29 & 28.0 & $6.7(2.9-15.7)$ & 65.2 \\
\hline Men & 20.5 & 1427 & 5 & 3.5 & 368 & 19 & 51.6 & 1795 & 24 & 13.4 & $14.7(5.5-39.4)$ & 73.8 \\
\hline Standardized & 20.4 & & & 3.8 & & & 25.4 & & & 12.6 & 6.7 & 53.6 \\
\hline Women & 29.7 & 2033 & 11 & 5.4 & 821 & 45 & 54.8 & 2854 & 56 & 19.6 & $10.1(5.2-19.5)$ & 73.1 \\
\hline Standardized & 30.2 & & & 5.3 & & & 52.0 & & & 19.7 & 9.8 & 72.9 \\
\hline Total & 26.2 & 3461 & 16 & 4.6 & 1189 & 64 & 53.8 & 4650 & 80 & 17.2 & $11.6(6.7-20.1)$ & 73.6 \\
\hline Standardized & 26.8 & & & 4.7 & & & 49.2 & & & 17.2 & 10.5 & 71.7 \\
\hline
\end{tabular}

CI, confidence interval; PAF, population attributable fraction; PYO, person years of observation.

generally the case by age groups but not by sex in both rural and urban areas. The PAF was higher than $50 \%$ in all groups except among women in the rural cohort. It was similar among men $(73.8 \%)$ and among women $(73.1 \%)$ in the urban cohort, but in the rural cohort, it was much higher among men $(66.6 \%)$ than among women $(42.1 \%)$. The PAF also indicates that the total death rate of adults 15-49 years in the general population in urban and rural populations was respectively $74 \%$ and $52 \%$ higher than it would have been without HIV. The probability of dying between 15 and 50 years converted from the observed death rates was $65 \%$ among those infected with HIV, $12 \%$ among the uninfected and $32 \%$ for the total. Figure 1 shows the respective probabilities by area of residence and sex.

Figure 2 shows that survival prospects were much poorer for infected men (Log Rank Mantel-Cox chi-square $=49.27, P<0.001)$ and women $(\log$ Rank Mantel-Cox chi-square $=95.24, P=0.001$ ) than for the uninfected. Kaplan-Meier survival curves in Figure 3 show that survival prospects for the infected in rural (Log Rank Mantel-Cox chi-square $=0.23, P=0.63$ ) and urban (Log Rank Mantel-Cox chi-square $=0.05, P=0.82$ ) areas were also similar. About $88.2 \%$ of the men were surviving after 2.83 years of follow-up compared with $91.3 \%$ of the women after 2.66 years of follow up in rural areas. In urban areas, $81.0 \%$ of infected men were surviving after 3.33 years of follow up compared with $81.6 \%$ of infected women after 3.50 years of follow up.

Table 3 shows the survival prospects of adults given as HR with $95 \%$ CI for each sub-group of selected covariates in relation to the reference sub-group. Age, marital status, self-rated health, years of education and HIV status were statistically significant in the univariate models. Sex and rural-urban residence were not. After adjusting the statistically significant univariate models with all other statistically significant covariates except for HIV status, the adjusted HR was lower. HR reduced by much more after also adjusting for HIV status. After also adjusting for HIV status, the HR for the divorced/separated/widowed reduced by about $68 \%$ compared with about $37 \%$ before also adjusting for it. The HR by educational level increased with an increase in the educational level before adjusting it for HIV status. After adjusting for HIV status, HR by educational level was highest among those with 1011 years of education, whereas it was highest among those with 12 or more years of education in the univariate model 
K. Dzekedzeke et al. Impact of HIV on adult mortality in Zambia

Figure I Probability of dying before 50 years by HIV status and area of residence for those aged 15-49 years.

Figure 2 Probability of survival between 1995 and 1999 by duration of follow up, HIV status and sex.
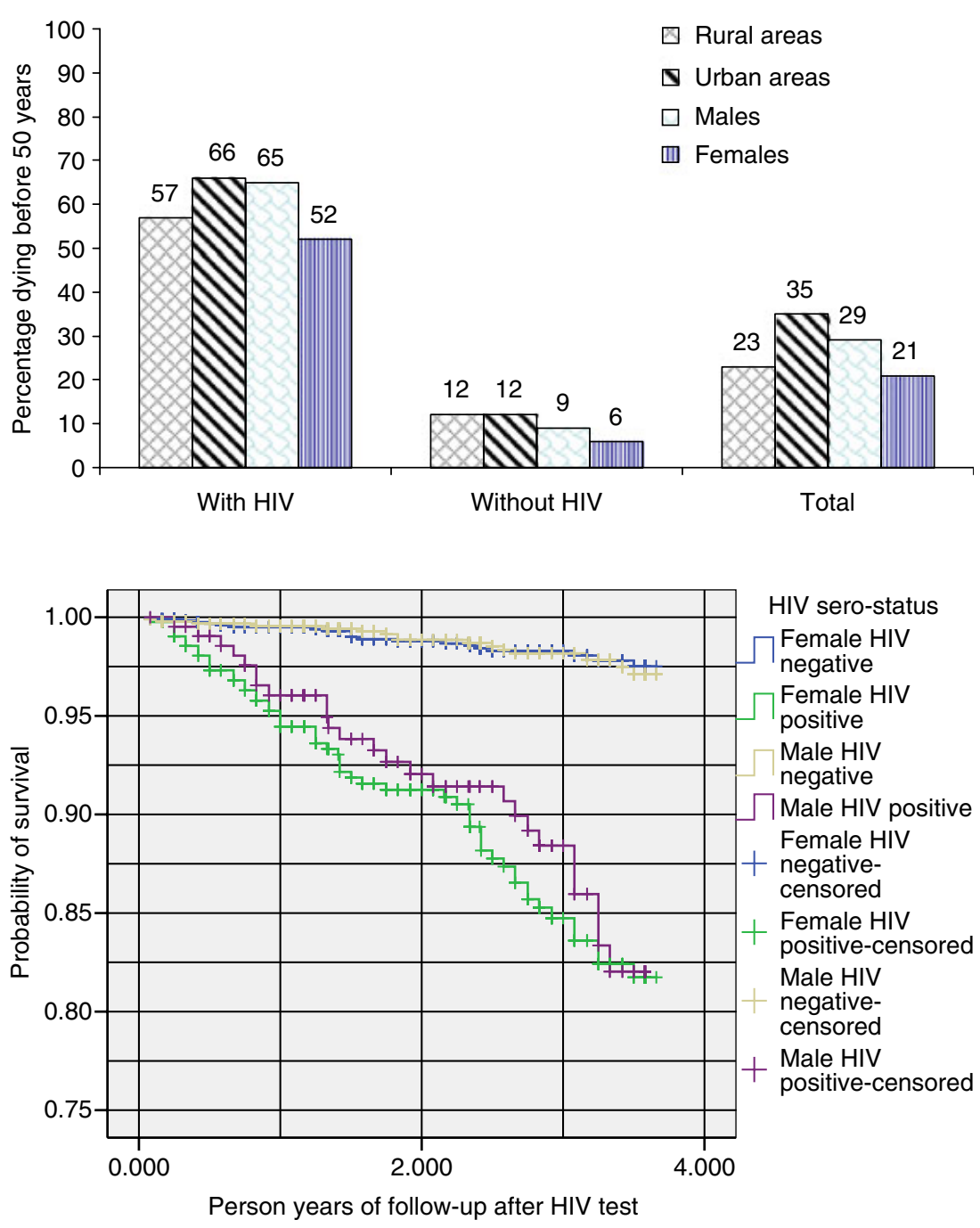

and in the multivariate model in which it was not adjusted for. The reduction in the HR among those infected with HIV by only $21 \%$ from $10.95(6.86-17.49)$ to 8.86 (5.4314.44) after adjusting for other statistically significant covariates of survival, namely age group, marital status, self-rated health and educational level shows that HIV status was the single most important factor affecting the survival prospects of the adults aged 15-49 years.

\section{Discussion}

The HIV status was the most important factor affecting the death rate of adults aged 15-49 years as shown by a number of indicators. The mortality proportion being attributed to HIV infection, the PAF was more than 50\% except among women in rural areas where the PAF was
$44 \%$. Respective death rates among men and women with HIV in the rural cohort were 15 and six times higher than among the uninfected. Similarly, they were 15 and 10 times higher among infected men and women than the uninfected in the urban cohort. Differences in the death rate patterns in the rural and urban cohorts suggest that there were differences in the epidemic in the two areas. The lower PAF and MRR in rural than urban areas indicate that the epidemic could have been more advanced in urban than rural areas.

As HIV infection was associated with almost $75 \%$ of the adult deaths, the insignificance of sex and rural-urban residence in affecting survival prospects should not be a surprise despite a contrary wealth of literature (United Nations Dept. of Economic and Social Affairs 1973). Typical survival prospects tend to be better among women 


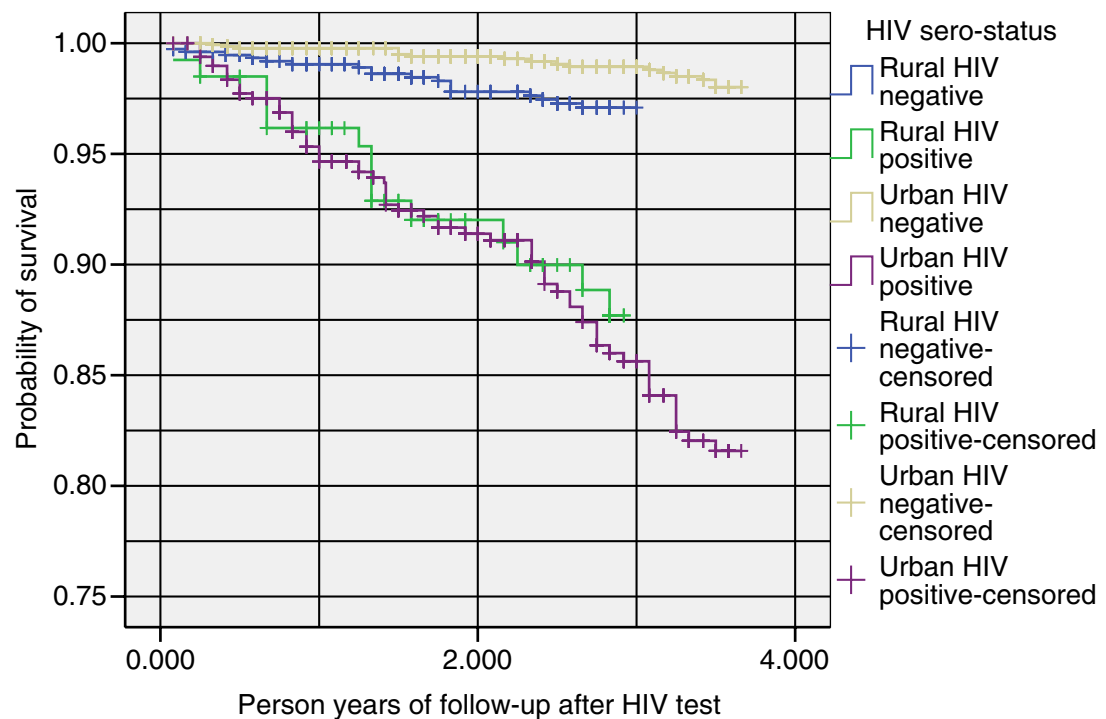

Figure 3 Probability of survival between 1995 and 1999 by duration of follow up, HIV status and residence. than men and in urban than in rural areas (United Nations Dept. of Economic and Social Affairs 1973). The reversal in this pattern in the total death rates in this cohort could be attributed to the HIV epidemic. Key evidence that HIV contributed to the reversal is shown by higher HIV prevalence among women than men, in urban than rural areas and also a higher death rate for the infected than the uninfected by these characteristics. Progression of HIV in an infected adult is also reasonably predictable (McCune 2001; Bajaria et al. 2002), and has been found not to be different among societies and socio-economic groups in the absence of intervention (Rutherford et al. 1990; Morgan et al. 1997; Morgan \& Whitworth 2001; Hira et al. 2003).

Trends in sex ratios from censuses of Zambia also suggest a higher increase in the death rate among women than men and possibly a higher death rate among women than men. The number of men per 100 women in the main reproductive age group of 20-44 years increased from 82.8 in 1969 [Central Statistical Office (Zambia) (1973)] to 85.1 in 1980 [Central Statistical Office (Zambia) (1985)], 90.6 in 1990 [Central Statistical Office (Zambia) (1995)] and to 93.4 in 2000 [Central Statistical Office (Zambia) (2003)]. The highest increase was between 1980 and 1990 when the increase in the HIV prevalence in most population groups was steep (U.S. Census Bureau 2006).

The total death rates among the infected were higher among women than men in this cohort but among men than women in other cohorts in sub-Saharan countries in Rakai (Sewankambo et al. 2000), Kisesa (Urassa et al. 2001) and Manicaland (Lopman et al. 2006). It suggests a major difference in the epidemic in the Zambian communities and those in other sub-Saharan countries. The death rate among the infected would be expected to be higher among men than women as in the other cohorts because men tend to be infected in older ages than women and older infection is associated with faster progression of HIV (Pezzotti et al. 1996; Anonymous 1998; Blaxhult et al. 1990; Carre et al. 1994; Darby et al. 1996; Rosenberg et al. 1994). However, a single universal HIV-related pattern of mortality is also unlikely and even a single infected population is likely to reveal different HIV-related sex-age patterns of mortality over the course of the epidemic owing to changes, such as in factors influencing exposure and changes in accessibility of health and nursing care by sex, age and socio-economic status.

The change in the HR pattern from being higher among those with 12 or more years of education in the univariate model and in the multivariate model before adjusting for HIV status, to being higher among those with 10-11 years of education after adjusting for HIV status, suggests that HIV infection accounted for mortality the most among those with the highest educational levels than among those with lower educational levels. HIV prevalence in the baseline survey was also the highest among those with the highest number of educational years (Fylkesnes et al. 2001). This was also the case in antenatal HIV prevalence surveys conducted in Zambia in 1994 (Fylkesnes et al. 1997). However, in the third prevalence survey in the same communities in 2003, the odds of HIV infection for those aged 15-49 years among males with 8-10 years, at least 11 years of education and females with at least 11 years of education were found to be significantly lower than for those with 0-7 years of education (Michelo et al. 2006a, b). With this trend, HIV-positive death rates by educational level in these communities might revert to the typical 
K. Dzekedzeke et al. Impact of HIV on adult mortality in Zambia

Table 3 Cox's proportional hazards model HR of death with 95\% CI by selected variables for total adults aged 15-49 years after 3 year follow-up

\begin{tabular}{|c|c|c|c|c|c|c|c|}
\hline \multirow{3}{*}{$\begin{array}{l}\text { Variables considered for } \\
\text { the models }\end{array}$} & \multirow{3}{*}{$\begin{array}{l}\text { Number of } \\
\text { deaths }\end{array}$} & & & \multicolumn{4}{|c|}{ Multivariate analysis } \\
\hline & & Univar & ate analysis & \multicolumn{2}{|c|}{$\begin{array}{l}\text { HR adjusted for all other } \\
\text { variables significant in the } \\
\text { univariate models but not } \\
\text { for HIV status }\end{array}$} & \multicolumn{2}{|c|}{$\begin{array}{l}\text { HR adjusted for all other } \\
\text { variables significant in the } \\
\text { univariate models includ- } \\
\text { ing for HIV status }\end{array}$} \\
\hline & & $P$ & $\operatorname{HR}(95 \% \mathrm{CI})$ & $P$ & $\operatorname{HR}(95 \% \mathrm{CI})$ & $P$ & $\operatorname{HR}(95 \% \mathrm{CI})$ \\
\hline \multicolumn{8}{|l|}{ Age group (years) } \\
\hline $15-24$ & 25 & & 1 & & 1 & & 1 \\
\hline $25-34$ & 37 & 0.000 & $2.72(1.64-4.52)$ & 0.075 & $1.76(0.95-3.27)$ & 0.392 & $1.29(0.72-2.31)$ \\
\hline $35-49$ & 35 & 0.000 & $3.00(1.79-5.01)$ & 0.111 & $1.71(0.80-3.32)$ & 0.154 & $1.57(0.84-2.93)$ \\
\hline \multicolumn{8}{|l|}{ Sex } \\
\hline Male & 31 & 0.110 & 1 & & & & \\
\hline Female & 66 & & $1.42(0.92-2.17)$ & & & & \\
\hline \multicolumn{8}{|l|}{ Residence } \\
\hline Rural & 17 & & 1 & & & & \\
\hline Urban & 80 & 0.070 & $1.64(0.96-2.80)$ & & & & \\
\hline \multicolumn{8}{|l|}{ Marital status } \\
\hline Never married & 22 & 0.000 & 1 & & 1 & & 1 \\
\hline Married & 59 & 0.000 & $2.42(1.49-3.95)$ & 0.189 & $1.53(0.81-2.86)$ & 0.599 & $1.17(0.65-2.10)$ \\
\hline Divorced/separated/widowed & 16 & & $6.39(3.36-12.18)$ & 0.000 & $4.12(1.93-8.81)$ & 0.051 & $2.07(0.10-4.30)$ \\
\hline \multicolumn{8}{|l|}{ Self-rated health } \\
\hline Good/excellent & 58 & & 1 & & 1 & & 1 \\
\hline Poor/fair & 39 & 0.000 & $2.30(1.53-3.45)$ & 0.001 & $2.01(1.34-3.03)$ & 0.017 & $1.66(1.10-2.51)$ \\
\hline \multicolumn{8}{|l|}{ Years of education } \\
\hline $0-9$ & 51 & & 1 & & 1 & & 1 \\
\hline $10-11$ & 17 & 0.099 & $1.59(0.92-2.75)$ & 0.205 & $1.43(0.82-2.50)$ & 0.368 & $1.29(0.74-2.25)$ \\
\hline $12+$ & 29 & 0.032 & $1.65(1.04-2.60)$ & 0.068 & $1.55(0.97-2.48)$ & 0.819 & $1.06(0.66-1.70)$ \\
\hline \multicolumn{8}{|l|}{ HIV status } \\
\hline HIV negative & 23 & & 1 & & & & 1 \\
\hline HIV positive & 74 & 0.000 & $10.95(6.86-17.49)$ & & & 0.000 & $8.86(5.43-14.44)$ \\
\hline
\end{tabular}

$\mathrm{HR}$, hazard rate; $\mathrm{CI}$, confidence interval.

pattern in which they tend to reduce with an increase in educational levels.

The significance of self-rated health as a predictor of mortality is in accordance with many studies showing it to have a unique relationship with mortality across continents and cultures (Idler \& Benyamini 1997). Consistent findings in this regard have been that of a dose-response relationship between the probability of death and self-rated health which was also revealed in this study (Idler \& Benyamini 1997). HIV infection was also found to be strongly associated with self-rated health in persons older than 24 years but not in those who were younger in the baseline population (Fylkesnes \& Siziya 2004; Siziya \& Fylkesnes 2005).

Interpretation of the results should take into account potential biases owing to loss of follow up. Death rates could be underestimated if HIV prevalence among those lost to follow up was higher than among those followed up. An opposite scenario is also applicable. Losses to follow-up could be caused by high proportions of terminally sick people migrating to their permanent homes especially from urban to rural homes with the hope of recuperating (Kitange et al. 1996; Nunn et al. 1997). This could bias the death rate estimates downward in the urban cohort. Healthy subjects could also migrate in search of employment, for instance, and death rates among them could be lower than among those followed up (Lopman et al. 2006). Loss to follow up might not have caused statistically significant bias in this cohort, given the insignificant difference in the HIV prevalence estimates between those who were followed up and those who were lost to follow up. If at all, mortality estimates among males were more likely to be underestimated than among females. The total HIV prevalence among males who were followed up (18.7\%) was somewhat lower, although not statistically significant, than among males lost to follow up $(23.8 \%)$. Among females, total HIV prevalence between those 
followed up (26.2\%) and those lost to follow up $(25.5 \%)$ was hardly different.

The inability to take into account the change in the HIV status of subjects between the baseline and follow-up surveys could also have distorted some patterns of mortality. Contrary to the typical pattern, death rates among the uninfected were higher in urban than rural areas and among women than men in both rural and urban areas. If the sex pattern of HIV prevalence for subjects who became sero-positive or got infected after the baseline survey was the same as for those who were infected in the baseline survey, then the death rate pattern by sex and rural-urban residence among those who were not infected in the baseline survey might appear to be the same as for those who were infected if the majority of deaths among them were also associated with HIV. In a hospital-based study at the referral hospital which serves some communities in the study areas, $35.3 \%$ of 85 patients who were HIV sero-negative when first examined got infected during a 12- to 39-month (means $=21.8$ months) period of observation (Hira et al. 1990). Given the long duration between the enrollment of the cohort and the follow up, such a scenario in the cohort was feasible.

In conclusion, HIV infection was the most important factor accounting for adult deaths in the communities. Typical death rate patterns by sex, rural-urban residence and level of education seem to have been reversed by the HIV epidemic. The PAF indicates that about three quarters and about half of the deaths among adults in urban and rural areas, respectively, would have been averted if HIV was controlled.

\section{Acknowledgements}

We thank all participants, counsellors, research assistants, the staff at the Zambia National AIDS/STD/TB and Leprosy Programme, and the staff of the Department of Virology, University Teaching Hospital, Lusaka, Zambia. The study was financed by the Norwegian Agency for development Co-operation (NORAD). Fellowship to write the paper was provided by the Norwegian Council for Higher Education's programme for Development Research and Education (NUFU).

\section{References}

Anonymous (1998) The AIDS incubation period in the UK estimated from a national register of HIV seroconverters. UK Register of HIV Seroconverters Steering Committee. Aids 12, 659-667.

Bajaria SH, Webb G, Cloyd M \& Kirschner D (2002) Dynamics of naive and memory CD4+ T lymphocytes in HIV-1 disease progression. Journal of Acquired Immune Deficiency Syndrome $30,41-58$.

Blacker J (2004) The impact of AIDS on adult mortality: evidence from national and regional statistics. Aids 18, S19-26.

Blaxhult A, Granath F, Lidman K \& Giesecke J (1990) The influence of age on the latency period to AIDS in people infected by HIV through blood transfusion. Aids 4, 125-129.

Carre N, Deveau C, Belanger F et al. (1994) Effect of age and exposure group on the onset of AIDS in heterosexual and homosexual HIV-infected patients. SEROCO Study Group. Aids 8, 797-802.

Central Statistical Office (Zambia) (1973) 1969 Census of population and housing, final report volume I - total Zambia. Central statistical office, Lusaka.

Central Statistical Office (Zambia) (1985) 1980 Census of population and housing, descriptive tables volume I. Central statistical office, Lusaka.

Central Statistical Office (Zambia) (1995) 1990 Post enumeration survey. 1990 Census Analytical Reports. Central Statistical Office, Republic of Zambia, Lusaka.

Central Statistical Office (Zambia) (2003) 2000 Census of population and housing; population projections report. Central statistical office, Lusaka.

Central Statistical Office (Zambia), Central Board of Health (Zambia) \& ORC Macro (2003) Zambia demographic and health survey 2001-2002. Central Statistical Office, Central Board of Health and ORC Macro, Calverton, Maryland, USA.

Darby SC, Ewart DW, Giangrande PL, Spooner RJ \& Rizza CR (1996) Importance of age at infection with HIV-1 for survival and development of AIDS in UK haemophilia population. UK Haemophilia Centre Directors' Organisation. Lancet 347, 1573-1579.

Fylkesnes K \& Kasumba K (1998) The first Zambian populationbased HIV survey: saliva-based testing is accurate and acceptable. Aids 12, 540-541.

Fylkesnes K \& Siziya S (2004) A randomized trial on acceptability of voluntary HIV counselling and testing. Tropical Medicine and International Health 9, 566-572.

Fylkesnes K, Musonda RM, Kasumba K et al. (1997) The HIV epidemic in Zambia: socio-demographic prevalence patterns and indications of trends among childbearing women. Aids 11, 339345.

Fylkesnes K, Ndhlovu Z, Kasumba K, Mubanga Musonda R \& Sichone M (1998) Studying dynamics of the HIV epidemic: population-based data compared with sentinel surveillance in Zambia. Aids 12, 1227-1234.

Fylkesnes K, Musonda RM, Sichone M, Ndhlovu Z, Tembo F \& Monze M (2001) Declining HIV prevalence and risk behaviours in Zambia: evidence from surveillance and population-based surveys. Aids 15, 907-916.

Gerstman BB (1998) Epidemiology Kept Simple: An Introduction to Classic and Modern Epidemiology. Wiley, New York.

Hira SK, Ngandu N, Wadhawan D et al. (1990) Clinical and epidemiological features of HIV infection at a referral clinic in Zambia. Journal of Acquired Immune Deficiency Syndrome 3, 87-91. 
K. Dzekedzeke et al. Impact of HIV on adult mortality in Zambia

Hira SK, Shroff HJ, Lanjewar DN, Dholkia YN, Bhatia VP \& Dupont HL (2003) The natural history of human immunodeficiency virus infection among adults in Mumbai. National Medicine Journal of India 16, 126-131.

Hu YR \& Goldman N (1990) Mortality differentials by marital status: an international comparison. Demography 27, 233-250.

Idler EL \& Benyamini Y (1997) Self-rated health and mortality: a review of twenty-seven community studies. Journal of Health and Social Behaviour 38, 21-37.

Kitange HM, Machibya H, Black J et al. (1996) Outlook for survivors of childhood in sub-Saharan Africa: adult mortality in Tanzania. Adult Morbidity and Mortality Project. BMJ 312, 216-220.

Levin ML (1953) The occurrence of lung cancer in man. Acta Unio Int Contra Cancrum 9, 531-541.

Lillard LA \& Panis CW (1996) Marital status and mortality: the role of health. Demography 33, 313-327.

Lopman BA, Barnabas R, Hallett TB et al. (2006) Assessing adult mortality in HIV-1-afflicted Zimbabwe (1998-2003). Bulletin of World Health Organization 84, 189-197.

McCune JM (2001) The dynamics of CD4+ T-cell depletion in HIV disease. Nature 410, 974-979.

Michelo C, Sandoy IF \& Fylkesnes K (2006a) Marked HIV prevalence declines in higher educated young people: evidence from population-based surveys (1995-2003) in Zambia. Aids 20, 1031-1038.

Michelo C, Sandoy IF, Dzekedzeke K, Siziya S \& Fylkesnes K (2006b) Steep HIV prevalence declines among young people in selected Zambian communities: population-based observations (1995-2003). BMC Public Health 6, 279.

Morgan D \& Whitworth J (2001) The natural history of HIV-1 infection in Africa. Nature Medicine 7, 143-145.

Morgan D, Maude GH, Malamba SS et al. (1997) HIV-1 disease progression and AIDS-defining disorders in rural Uganda. Lancet 350, 245-250.

Mulder DW, Nunn AJ, Kamali A, Nakiyingi J, Wagner HU \& Kengeya-Kayondo JF (1994) Two-year HIV-1-associated mortality in a Ugandan rural population. Lancet 343, 1021-1023.

Noale M, Minicuci N, Bardage C et al. (2005) Predictors of mortality: an international comparison of socio-demographic and health characteristics from six longitudinal studies on aging: the CLESA project. Experimental Gerontology 40, 89-99.

Notkola V, Timaeus IM \& Siiskonen H (2004) Impact on mortality of the AIDS epidemic in northern Namibia assessed using parish registers. Aids 18, 1061-1065.

Nunn AJ, Mulder DW, Kamali A, Ruberantwari A, KengeyaKayondo JF \& Whitworth J (1997) Mortality associated with HIV-1 infection over five years in a rural Ugandan population: cohort study. BMJ 315, 767-771.

Peduzzi P, Concato J, Feinstein AR \& Holford TR (1995) Importance of events per independent variable in proportional hazards regression analysis. II. Accuracy and precision of regression estimates. Journal of Clinical Epidemiology 48, 1503-1510.

Pezzotti P, Phillips AN, Dorrucci M et al. (1996) Category of exposure to HIV and age in the progression to AIDS: longitudinal study of 1199 people with known dates of seroconversion. HIV Italian Seroconversion Study Group. BMJ 313, 583-586.

Pictet G, Le Coeur S, M'Pele P, Brouard N \& Lallemant M (1998) Contribution of AIDS to the general mortality in Central Africa: evidence from a morgue-based study in Brazzaville, Congo. Aids 12, 2217-2223.

Piot P, Plummer FA, Mhalu FS, Lamboray JL, Chin J \& Mann JM (1988) AIDS: an international perspective. Science 239, 573-579.

Preston SH, Heuveline P \& Guillot M (2001) Demography: Measuring and Modeling Population Processes. Blackwell Publishers, Malden, MA.

Quinn TC, Mann JM, Curran JW \& Piot P (2001) AIDS in Africa: an epidemiologic paradigm. 1986. Bulletin of World Health Organization 79, 1159-1167.

Rosenberg PS, Goedert JJ \& Biggar RJ (1994) Effect of age at seroconversion on the natural AIDS incubation distribution. Multicenter Hemophilia Cohort Study and the International Registry of Seroconverters. Aids 8, 803-810.

Rutherford GW, Lifson AR, Hessol NA et al. (1990) Course of HIV-I infection in a cohort of homosexual and bisexual men: an 11 year follow up study. BMJ 301, 1183-1188.

Sewankambo NK, Wawer MJ, Gray RH et al. (1994) Demographic impact of HIV infection in rural Rakai district, Uganda: results of a population-based cohort study. Aids 8, 1707-1713.

Sewankambo NK, Gray RH, Ahmad S et al. (2000) Mortality associated with HIV infection in rural Rakai District, Uganda. Aids 14, 2391-2400.

Siziya S \& Fylkesnes K (2005) Impact of HIV-1 infection on selfrated health in a high-prevalence population with low awareness of own HIV status. Norwegian Epidemiology 15, 165-173.

Timaeus IM (1998) Impact of the HIV epidemic on mortality in sub-Saharan Africa: evidence from national surveys and censuses. Aids 12, S15-27.

Timaeus IM \& Jasseh M (2004) Adult mortality in sub-Saharan Africa: evidence from demographic and health surveys.

Demography 41, 757-772.

Todd J, Balira R, Grosskurth H et al. (1997) HIV-associated adult mortality in a rural Tanzanian population. Aids 11, 801-807.

United Nations Dept. of Economic and Social Affairs (1973) The Determinants and Consequences of Population Trends: New Summary of Findings of Interaction of Demographic, Economic and Social Factors. United Nations, New York.

Urassa M, Boerma JT, Isingo R et al. (2001) The impact of HI$\mathrm{V} / \mathrm{AIDS}$ on mortality and household mobility in rural Tanzania. Aids 15, 2017-2023.

U.S. Census Bureau, P. D., International Programs Center (2006) HIV/AIDS Surveillance Data Base. Census Bureau, Population Division, Health Studies Branch, U.S.

Corresponding Author Kumbutso Dzekedzeke, Central Statistical Office, Lusaka, Zambia. Tel.: +260 979701499; Fax: +260 211253468; E-mail: Kumbutso.Dzekedzeke@student.uib.no 